\title{
Filasafia:
}

\section{Sobre una Definición de la Lógica}

\author{
Por Francisco Miró Quesada.
}

Una de las consecuencias más sorprendentes del gigantesco movimiento histórico-filosófico que culmina en el nacimiento de la lógica moderna, es que toda definición de la lógica se revela como un intento frustrado de encauzar dentro de estrechos marcos un contenido ilimitado que rebasa toda determinación. La lógica ya no es aquella disciplina cerrada, como creyó Kant, que desde los tiempos de Aristóteles no había hecho iningún progreso importante y que no podría hacer ningún progreso en los siglos venideros. Hoy día se nos aparece como una disciplina en pleno crecimiento, como una poderosa marejada teórica que rompe todos los diques y cuyo término evolutivo es tan lejano como el de la física o la matemática. Sus límites se han hecho difíciles de precisar y para muchos autores se confunde con las ciencias matemáticas (Russell). Para otros no puede hacerse ninguna diferenciación entre ella y la ontología formal (Husserl). Y no faltan pensadores que sostienen que la lógica es por principio indefinible y que no es tampoco necesario buscarle una definición pues, al par de las disciplinas positivas sigue su propio curso regido por leyes constitutivas que la conducen por el "seguro camino de la ciencia". Por otra parte, la reciente formalización hecha por von Misses, Jeffreys, Reichenbach y especialmente por Carnap, de la lógica inductiva complica el problema, pues hasta hace pocos años se consideraba que la lógica inductiva pertenecía más a la teoría del conocimiento que a la lógica misma, mientras que hoy día, después de las investigaciones mencionadas, se ve con toda claridad que dicha lógica tiene tan pleno derecho a llamarse lógica como la deductiva. 
Reconociendo que, en el momento actual de las investigaciones, es imposible llegar a una definición completa de la lógica, creemos que empleando determinados conceptos de reciente aparición, es posible dar una definición que si no agota todas las especies, tiene la ventaja de incluir tanto a la lógica deductiva como a la inductiva y a una serie de capítulos, como la teoría de las clases y de las relaciones, que se consideran generalmente como partes de la ontología formal. De esta manera, pensamos ofr de partida que le permita, conservando la amplitud de miras, considerar a la lógica como una disciplina unitaria, que a pesar de sus variaciones presenta un núcleo común a sus más diversas manifestaciones. Sobre este punto de partida, podrá adentrarse en el complejo bosque del moderno "corpus log icum" sin perderse desde el comienzo, y podrá descubrir una evidente relación entre copítulos que aparentemente no la tienen. Con esta base podrá profundizar sus estudios hasta llegar a la etapa en que pueda juzgar por sí mismo el valor de nuestra definición.

Creemos que una definición a la vez rigurosa y amplia que se puede dar de la lógica es la siguiente: la lógica es la disciplina que estudia las relaciones proposicionales aléthicas (1).

Por relación proposicional aléthica debe entenderse una relación hipotética entre la verdad de las proposiciones, tal que, la verdad de las unas, sirve de fundamentot (oc sealde base baunto de partida) para establecer la verdad de las etras. Por ejm.enoel caso de la subor. dinación (cuadro de Boetio), tenemos una relación aléthica entre dos proposiciones, la universal afirmativa y la particular afirmativa. De la verdad de la proposición "todos los hombres son mortales" se desprende la verdad de la proposición "algunos hombres son mortales". La relación aléthica consiste pues en una relación hipotética de fundamentación de verdad. No es una relación entre dos (o más) proposiclones verdaderas, es una relación entre dos verdades posibles, tal que si una de ellas quedara establecida, la otra también podrá afirmarse. En el silogismo, por ejm. existe una relación aléthica entre tres proposiciones, entre las dos premisas y la conclusión.

Naturalmente, al hablar de una relación entre la verdad de las proposiciones, se ha hablado en sentido amplio. En la palabra verdad se ha incluído también la falsedad, porque la falsedad puede siempre

(1) Hemos tomado la palabra "aléthico" (aunque con un sentido algo diferente) del lógico inglés Von Wright. 
considerarse desde el punto de vista de la verdad. No hay hasta el presente definición más rigurosa de la falsedad que la que la considera, simple y llanamente, como la negación de la verdad. Por eso, por relación aléthica, debe entenderse toda relación hipotética entre las verdades o las falsedades de las proposiciones.

En nuestra definición quedan incluídos todos los capítulos de la lógica (tanto clásica como moderna). Porque, aunque después veremos que se trata de una relación aún más amplia, la relación deductiva entre dos o más proposiciones queda incluída dentro de nuestra definición. Incluso, es fácil darse cuenta, que, al haber adoptado la definición propuesta, hemos dado preeminencia al aspecto inferencial de la lógica (2). Pero para comprender, digamos, una relación deductiva entre dos proposiciones, es necesario conocer su estructura. Por lo tanto, no puede conocerse este tipo de relación sin conocer con anterioridad la estructura de la proposición (juicio) y la función que desempeñan los términos (conceptos) dentro de ella. Tenemos así los tres capítulos fundamentales de la lógica clásica, aunque la teoría del juicio y del concepto, desempeñen, en relación a la definición adoptada, un papel introductorio.

Nuestra definición tiene además otra ventaja, que en ella quedom incluídos los dos grandes aspectos de la lógica: el deductivo y el inductivo. Porque hemos dicho que una relación proposicional aléthica es una relación hipotética de fundamentación entre la verdad de dos - más proposiciones. Pero no hemos especificado el tipo de fundamentación. Si tratamos "de especificarlo, encontraremos que la fundamentación de la verdad de una proposición por medio de la verdad de otra (tomamos el caso de dos proposiciones por ser el más simple, pero todo lo que se diga para dos proposiciones puede decirse para un número indeterminado - aunque naturalmente finito- de proposiciones) sólo se puede hacer de dos maneras: o bien se trata de una fundamentación necesaria o bien se trata de una fundamentación probable. En el primer caso se trata de una conexión deductiva entre ambas proposiciones; en el segundo caso se trata de una conexión inductiva. Si la verdad de una proposición se deriva en forma necesaria de la verdad de otra, se dice que la verdad de la primera ha sido deducida de la verdad de la segunda. En este sentido consideró la lógica clásica a la deducción, y exactamente en el mismo sentido la considera la lógica moderna.

(2) Esto está naturalmente de acuerdo con el espiritu de la lógica moderna. 
Pero la verdad de una proposición puede derivarse en forma no necesaria, es decir en forma solamente probable de la verdad de otra. En este caso se dice que se ha derivado inductivamente de la verdad de aquella. La lógica clásica no tuvo un concepto verdaderamente claro de la inducción y la mayoría de las veces planteó el problema más desde un punto de vista epistemológico que lógico. El problema de la inducción fue visto como la necesidad de justificar el paso de un conjunto de verdades particulares a una verdad universal y necesaria. $Y$ esto no es un problema de lógica, pues no existe ninguna relación entre las proposiciones particulares y la proposición universal que justifique tal paso. Por otra parte, a pesar de todos los esfuerzos de los lógicos y de los filósofos no fue posible encontrar la justificación buscada, porque no existe tal justificación. No hay ninguna base para pasar de un conjunto de verdades particulares a una verdad universal necesaria. Por esta razón, los lógicos modernos consideraron durante largo tiempo que la lógica no tenía nada que ver con la inducción. Ultimamente, gracias a los trabajos de Jeffreys, de Reichenbach, y fundamentalmente de Carnap (3), se ha logrado ver con toda claridad que la relación de verdad entre un conjunto de proposiciones particulares y una proposición universal, es una relación de probabilidad. Esta relación puede determinarse con loda exactitud, de manera que se presenta como una relación unívoca, mediante la cual, de la verdad de un conjunto de proposiciones, Cse puede Ginferirs la verdad de una proposición con un valor dada dei probabilidad $E_{1}$ "conjunto de proposiciones particulares que sirve como punto de partida, se denomina "evidencia inductiva" '(Carnap). Si la experiencia inductiva está integrada por pocas proposiciones (puede ser incluso una sola), la pro. babilidad de que la proposición inductiva sea verdadera, será pequeña. Conforme va aumentando el conjunto de proposiciones que integra la evidencia inductiva, irá aumentando la probabilidad de la verdad de la proposición inductiva.

Cuando la probabilidad de la verdad de una proposición es máxima, es decir cuando su verdad se deriva necesariamente de la verdad de otra $u$ otras, entonces se trata de una derivación deductiva. La deducción puede considerarse así, como un caso particular de la in-

(3) Theory of probability. Jefîreys. Oxford University Press 1948. The Theory of probability. Reidienbach. California University Press 1949.- Logical foundations of Probability. Carnap. University of Chicago Press, 1950. 
ducción, como un caso en el cual, la relación de probabilidad entre la evidencia inductiva y la proposición inducida es máxima.

Vemos pues, que nuestra definición incluye ambos tipos de lógica: la deductiva y la inductiva. En ambos casos la relación entre los proposiciones que sirven de punto de partida y las proposiciones cuya verdad se pretende derivar de las primeras, es una relación aléthi$\mathrm{ca}$, es decir una relación hipotética de fundamentación entre la verdad de las proposiciones. En el caso de la lógica deductiva se trata de una relación necesaria; en el caso de la lógica inductiva, de una relación probabilística.

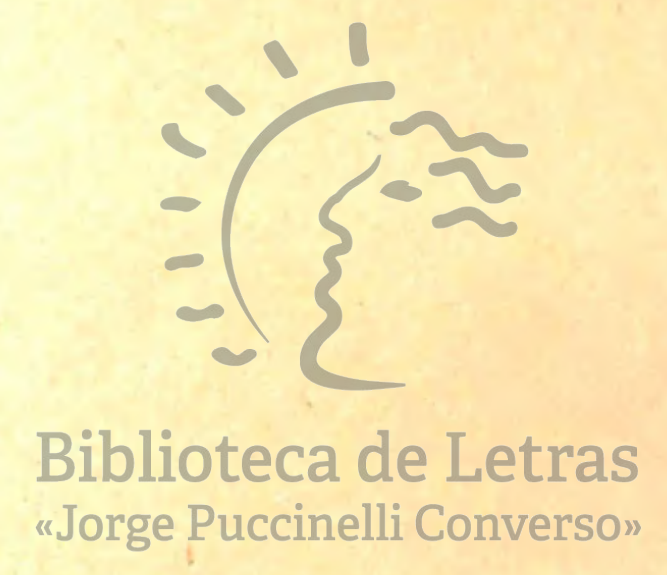

